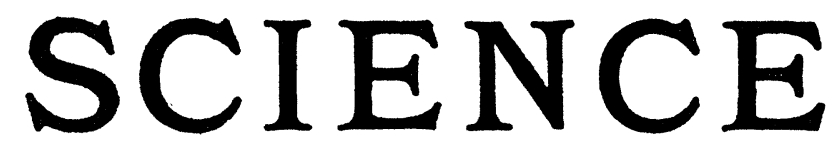

A Weekly Journal devoted to the Advancement of Science, publishing the official notices and proceedings of the American Association for the Advancement of Science, edited by J. McKeen Cattell and published every Friday by

\section{THE SCIENCE PRESS}

11 Liberty St., Utica, N. Y. Garrison, N. Y,

New York City: Grand Central Terminal

Single Copies, 15 Cts.

Annual Subscription, $\$ 6.00$

Application made for transfer of entry to Utica, N. Y., as second-class matter.

\begin{tabular}{lll}
\hline Vol. IV JANUARY $27,1922 \quad$ No. 1413 \\
\hline
\end{tabular}

The American Association for the Advancement of Science:

The Trend of Earth History: DR. ELIOT BLACKWELDER

83

On the Differential Effects of the Influenza Epidemic among Native Peoples of the Pacific Islands: Professor Henty E. CRAMPTON

Presentation to Professor Emerson: ЈoHN

M. Clarke

Scientific Events:

Dr. White's Gift to Morgantown and the University of Virginia; Expeditions of the Field Museum of Natural History; The American Engineering Council; Associateship in the American Association for the Advancement of Science.

Scientific Notes and News..

University and Educational Notes

Discussion and Correspondence:

Discovery of Gigantic Footprints in the Coal Measures of Kansas: H. T. Martin. Liesegang Ring Formation: DR. HUGH A. MCGUIGAN

Special Articles :

The Identity of Certain Yellow Pigments in Plants and Animals: Professor GEORge B. RIGG. Rate and Mode of Soil Deposition in the Palouse Area of Washington and Idaho: Professor P. P. Peterson...... 101

The American Association for the Advancement of Science:

Report of the Treasurer; Financial Report of the Permanent Secretary.

The American Society of Naturalists: ProFESSOR A. FRANKLIN SHULL. 105

\section{THE TREND OF EARTH HISTORY ${ }^{1}$}

Some years ago a witty member of the mining engineering profession read a paper before the Canadian Institute of Mining Engineers, picturing geologists, and particularly historical geologists, as a group of romancersthe lineal descendants and heirs of the old professional story-tellers of the middle ages. $\mathrm{He}$ accounted for the general popularity of the subject of geology by the fact that every one loves a story-teller, while but few people are interested in questions of cold fact.

Nearly all opinions, correct or otherwise, are based upon a modicum of fact; and so, for this impression of historical geologists as dreamers and story-tellers, there is a certain foundation in reality. It will scarcely do, however, to accept so distorted a picture as even an approximation to the truth.

Are the data with which the student of Earth history works so obscure, so fragmentary and so equivocal that his conclusions are not entitled to confidence? In part, Yes; but in large measure, No. They are in fact much like the data of human history, and partieularly of archeology. That they are not exact quantitative evidence is true, and this tends to make them seem untrustworthy in the eyes of the student of the more exact sciences. Nevertheless, the data are real, and safe conclusions may be drawn from them if care and due caution are applied to the operation. Furthesmore, the solving of one problem often leads to the solution of another which had previously resisted all attempts at interpretation. In spite of the obvíous inoompleteness of the geo. logic record, we nevertheless have a large number of clearly ascertained facts about the physical and biologic history of the earth, and

1 Address of the Vice-President and Chairman of Section E-Geology and Geography, American Association for the Advancement of Science, Toronto, December 28, 1921. 
ever some hints about its birth and antecedents.

The biologic phase of the subject overshadowed the physical in the minds of the historical geologists of the nineteenth century so largely that we now know more about the character and sequence of organic forms than about other phases of the Earth's history. Courses in historical geology have generally been taught by paleontologists, and the history of animals and plants fills most of the pages devoted to historical geology in textbooks and manuals. In the last few decades, however, more and more attention has been given to the nature and sequence of the climates, physiographic changes, volcanic outbursts and other physical events; and our knowledge of this phase is now growing so rapidly that it bids fair to overhaul and pass the earlier wave of biological study. To appreciate the truth of this statement, it is only necessary to scan the list of papers that have been published in recent years on such subject as unconformities, sedimentation, orogenic epochs, paleogeography, physiographic historv, glacial epochs, and the like.

The study of the physical history of the Earth assumes new aspects from decade to deeade, as a question here and there is answered and other problems arise out of the interaction of newer ideas. One of the commonest questions which geologists are asked is - "How old is the earth?" and "How many years have elapsed" since this or that event in its history took place? The question has been attacked from many angles, and although exact calculations are not yet and perhaps never will be possible, we may have increasing confidence in the general character of the returns.

Counting the growth-rings in the big trees of California shows that some of those giant growths are more than 4,000 years old, and yet no marked change has taken place in the surface of the land on which they stand since they sprouted from the soil.

Baron De Geer, after a most painstaking study of the laminated glacial clays of northwestern Europe, seems to have compiled a definite record of seasonal changes of deposition covering some six or seven thousand years, during which certain post-glacial lakes were being filled with deposits of silt.

Less accurate estimates of geologic time have been based on recessions of Niagara Falls and other cataracts. These problems are usually complex and the factors not all well known. Hence, estimates of the number of years since the ice sheet left Niagara vary all the way from 7,000 to 50,000 years. Nevertheless, this gives a general order of magnitude which is of value. The mean of the two extremes is probably not very far from the truth.

The most complete part of our geologic record is the composite pile of strata of the sedimentary rocks. Many attempts have been made to translate the thickness of these beds into terms of years, but our knowledge of the rate at which sediments accumulate under various conditions is still far too inaccurate. We know rates in certain isolated instances, but they vary within wide limits, and we do not yet understand the factors that govern the variations. There is good reason to believe, however, that the rate of deposition generally has been overestimated, and hence the periods of time have been made too short.

Within the last fifty years, the various estimates which have been made of the time represented by the Paleozoic, Mesozoic and Cenozoic eras have varied between three million years for the lowest and six thousand million years for the highest. The average of twenty such estimates is about 250 million years, but most of the individual figures are about 100 million or less.

On the whole, from decade to decade there has been a disposition to lengthen the estimates, as the testimony of the stratigraphie column became better understood. In 1893, Walcott allowed 45 to 70 million years for the three eras. In 1899 Geikie estimated 100 million years. In 1913, Holmes calculated an average of about 300 million years for the same group of periods, and, in 1916, Barrell suggested 360 to 540 million years as the best estimate based on the sedimentary deposits. This tendency to recognize more clearly the immense duration of the various geologic periods has been due largely to a growing un- 
derstanding of the many diatems, or interruptions in the stratigraphic column, as well as variation in the rate at which different types of sediments have been laid down.

Soon after the discovery of the fact that radium undergoes an exceedingly slow decomposition leaving helium and lead as products, it was found that the minerals of the oldest rocks contained more helium and lead than those of younger rocks. The following are a few examples selected from the calculations by Strutt expressed in terms of the time from certain periods down to the present:

1. Miocene ........................ 6 million years

2. Upper Carboniferous........146 million years

3. Early pre-Cambrian..........710 million years

Holmes recognized that much of the gas emitted might have escaped during the subsequent existence of the minerals. Using the less migratory element, lead, as a basis of calculation, he reached the figures 1,000-1,600 millions years for the age of certain minerals from the Archean rocks. It is particularly significant, that the testimony of different minerals from the same intrusion, considering the errors expectable in analytic work, generally agrees rather closely; and there is almost as good a correspondence between the lead ratios of minerals of the same general age but from widely separated localities. According to Barrell's interpretation, the rare-earth minerals of the Llano uplift in central Texas contain uranium-lead indicating an age of about 1,125 million years. They are roughly of middle pre-Cambrian Age. Unless there are concealed sources of error in the careful work of our best radiologists, we seem justified in accepting their estimates as fairly satisfactory approximations-very much the best we have ever had-which indicate that the Mesozoic rocks are tens of millions, the Paleozoic rocks hundreds of millions, and the most ancient pre-Cambrian rocks more than 1,500 millions of years old.

Reviewing these attempts to express the history of the earth in terms of years, we find that from the time of Archbishop Ussher and his estimate of 5,700 years for the total history of the earth up to his day, or even Lord Kelvin who allowed 20 to 40 million vears for the entire evolution of the planet, the tendency has been to greatly increase our estimates of the length of time involved in even the later part of the Earth's history; for we must not forget that the time from the earliest Archean period to the present is probably very short, as compared with the time that has elapsed in the formation of the earth as a planet and is to elapse before its final refrigeration-if such is ever to occur. The contemplation of such vast lapses of time makes the brief span of human history seem absurdly short. It is difficult to realize, when studying "history," commonly so-called, that we are reading only the latest chapter of the last volume of a great series of tomes numerous enough to fill a large library.

The physical events that crowded this tremendous space of years are being made known as geologic field studies progress. Among them are the orogenic disturbances, or diastrophic revolutions, when long winding wrinkles were builged upon the Earth's surface, only to waste away under the slow attack of the weather. While they are in this process of decay, we eall them mountain systems. At such times, the shallow epicontinental seas are generally withdrawn into the ocean basins, the average height of the continental masses above sea-level is increased, and the work of erosion accelerated.

That part of North America now occupied by the Rocky Mountain System was, from before the Cambrian down to the Cretaceous period, for the most part a region of plains or low hills, undergoing èither general erosion or decomposition. Much of the time it was seabottom. Then followed a period of profound disturbance. The stratified rocks were wrinkled into folds, and their foundation of ancient crystalline rocks compressed and mashed beneath them. Great slices were sheared over the subjacent mass for many miles. Molten lava welled up into the disturbed formations and even burst forth on the surface scattering einders and volcanic dust far and wide. Remnants of the lava flows and stocks still mark the sites of voleanic cones which have since been demolished. This disturbance subsided, but was repeated soon afterward at the close 
of the Paleocene Period. The deformation was again renewed in the Miocene period and in a milder form still more recently. From the bulged and wrinkled tract thus prepared, the Rocky Mountains, as we know them today, have been carved by the combined agencies of erosion.

By contrast, on the eastern slope of North America, periods of relative stability in the crust alternated with these compressive disturbances, from a remote pre-Cambrian time down to about the close of the Paleozoic era. Since then the region has been comparatively quiet, and its history is chiefly the story of the erosion of the surface, modified from time to time by slight and gentle uplifts and subsidences of broad areas.

These are examples of a great geologic principle. All regions of the globe have had similar periods of disturbance alternating with those of quiet, but as to time and intensity they have differed among themselves. In the earlier days of geology these crumpling disturbances were usually ascribed to the cooling and consequent shrinkage of the globe. Other hypotheses are now in the field, and the contest is still in full swing. Whatever their cause, we do not find much evidence of a general decrease in the activity of such internal earth forces. On the contrary, the middle Tertiary revolution was one of the most widespread and intense of which we have any record. There have been many fluctuations but no general trend.

Volcanic action likewise varies in intensity, and transfers its activity from one region to another from period to period; generally accompanying but locally ignoring the diastrophic disturbances. Yet, on the whole, the volcanic activity of the last two geologic periods is equal in intensity and widespread distribution to anything known to us in earlier periods.

The demolishing of the hills and mountains by streams, winds, glaciers, and the other erosive agencies proceeds most actively during the periods of crumpling. At such times broad, flat-bottomed valleys are planed off only on the outcropts of the softest rocks. The wearing away of the harder masses proceeds at a much slower pace. Before such plains can be extended over the more resistent outcrops, the heaving and sagging of the uneasy earth interrupt the process and rejuvenate the erosion cycle.

Eventually the internal unrest subsides; the body movements virtually cease for a long period until renewed in the oncoming of the next orogeny. In this period of relative quiet, the erosive agencies are able to reduce to comparative flatness not only the outcrops of the soft, but also the harder rocks, until peneplains of broad extent have been produced. Only the hardest masses and those farthest removed from the main drainage channels continue to stand out as mountains. The early Cambrian and the Jurassic periods saw peneplains extended over most parts of North America of which there is sufficient record. Meanwhile, the adjacent seas were gradually being filled with the detritus swept from the land, and were in consequence creeping out upon the continental platforms in the form of shallow seas.

To-day we evidently are living in the midst, or perhaps near the close, of one of the lesser periods of internal disturbance. For this reason our broad plains of erosion, such as the Mississippi Basin, Central Russia and northwest Siberia are limited for the most part to the outcrops of soft rocks. Nevertheless, we appear to have, even to-day, in central Canada and eastern Siberia ancient peneplains, on hard rocks, which have been so little dusturbed and dissected that they still retain in large measure their distinctive character.

For a hundred vears or more paleontologists have been gathering and assembling information regarding the kinds of animals and plants represented by the fossils in the rocks. From them we learn the distribution of these plant and animal societies both in space and time. When enough information has been gathered regarding the distribution of the marine sediments and faunas of a particular age, we are in a position to map, at least roughly, the sea and land areas of the time. Such maps have been made within the last few years in considerable variety and for more than one of the continents. They are admittedly crude approx- 
imations to the truth; yet they show certain general facts that are fairly well substantiated. The more detailed studies of this kind have made us realize that throughout the recorded part of geologic history there have been alternate expansions and contractions of the oceans, with reciprocal changes in the land areas. Schuchert has estimated that about the middle of the Ordovician time the sea covered two thirds or more of what we now call North America, as well as large parts of other continents. It was one of the distinctively oceanic epochs. On the other 'hand, the epochs that began and terminated the Paleozoic era were times of diastrophic activity marked by such extreme contractions of the ocean-covered areas that we can find on our present lands only small traces of the marine strata of those ages. The rest of them are doubtless buried beneath the present oceans.

These oscillations of the shore-line seem to be wholly irregular and pulsating. We can discern no definite tendency toward either a progressive contraction or a progressive expansion of the ocean. If there be such a tendency, it must be so gradual that even many geologic periods are not sufficient to reveal its nature to us. Only on theoretical grounds may we suspect that the oceans are constantly growing a little larger, for they are receiving from time to time water derived from the steam of volcanic eruptions; and there is reason to think that much of this water is a real contribution from the interior of the earth and that it has never before been a part of the hydrosphere.

We have come to anderstand that the hills, mountains, valleys and other topographic details of the land are almost entirely the result of what James Geikie has aptly called "land sculpture." Streams of water, the wind, glaciers, the waves of the sea and still other agencies combine their efforts to produce a composite result, which in some regions may be more the work of one agency and in others largely the work of another.

On the average these various processes of erosion seem to work with exceeding slowness. The pyramids of Egypt, now nearly six thousand years old, have suffered only trivial wear from the continual sandblast action of the desert winds through all those centuries. From estimates of the amount of material carried out by the streams to the ocean in solution and in suspension each year, we may calculate that the continents are being worn away at a rate which, if evenly distributed, would be sufficient to lower the land surface one foot in about every 10,000 years; but we are well aware that this erosion is much more rapid in a few specially favored localities than elsewhere and hence that over most of the land the rate of denudation is correspondingly slower.

On the other hand, we have elear evidence that these processes have brought down nearly to base-level large areas of land surface in a mere fraction of one of our geologic periods. The Paleozoic rocks of southern Oklahoma, compressed, folded and strongly elevated late in the Pennsylvanian or Carboniferous period, were beveled off to such an extent before the Permian period that the rocks of that age now rest upon the truncated edges of the older beds, although but a fraction of the Pennsylvanian period intervenes between the two events. In the Rocky Mountains of Colorado and Wyoming an interval of active erosion, following the first uplift of the Rocky Mountain system, stripped off the many thousands of feet of sedimentary formations to such an extent that the old pre-Cambrian crystalline terranes were exposed to erosion before the oldest Tertiary strata were deposited. This lapse of time, although amounting, no doubt, to hundreds of thousands of years, was so short that it now appears to us only the quick transition between two of our commonly recognized geologic periods. Few things show more clearly how coarse are the divisions on the great time-scale of earth history.

Our knowledge of the climates of even the better known periods of geologic history has lagged behind that of the physiographic and biologic changes. For a long time inferences were drawn almost entirely from the nature of the fossils. Coral reefs were understood to mean tropical or sub-tropical climates. The bones of reindeer in France and of musk-oxen in Kentucky indicated a colder climate than that enjoyed by the same regions to-day. On the other hand, the leaves of palms and breadfruit trees, preserved in lignite beds on the coast of Greenland, suggested a much milder 
climate there, in one of the early Tertiary epochs. Unfortunately, many formations contain no fossils or only such as have no clear significance.

More recently the nature of the sedimentary rocks themselves has been recognized to be indicative of climate. It was pointed out long ago that ancient glacial beds in India showed a period of cold climate in a region which is now warm. Beds of rock salt in the Permian strata of Germany were correctly interpreted to mean arid conditions. But it is only recently that the climatic relations of the less extreme, through much more common, types of sediments have come to be understood in a general way. In the not distant future we may expect to read the climatic significance not only of all terrestial deposits but to some extent even of the marine formations, although the latter are much less affected by changes of climate.

An individual rock formation is itself a more or less legible record of the local climatic conditions at the time and place of its origin. Such local climates must have been related in considerable measure to temporary features of the land topography. Thus, some of the deposits which indicate aridity were probably laid down on the lee sides of high mountain ranges. Others were due to the prevailing distribution of oceans and currents. It has long been recognized that the broad expansion of seas in the Ordovician and Silurian periods must have favored an untrammelled circulation of currents capable of equalizing temperatures between the tropical and polar regions far more effectively than is possible to-day.

In spite of such local influences on climate, we may, by considering the climatic implications of all the formations of a particular epoch, gain a general impression of the average climate of the globe for that time, and these average climates may be compared among themselves and with that of the present. Although only a good beginning of this work has been made thus far, it should be but a few years till we shall understand ancient climates at least as well as we already know ancient land configuration.

All that we have learned thus far about the earth's climatic history goes to show that, ever since the earliest periods of which we have a sufficient record, there have been frequent oscillations between colder and warmer and between moister and drier climates, but always within narrow limits. At no time does the climate appear to have been inimical to life over all or even half of the globe. To-day over a considerable part of the land surface it is so dry, as in central Arabia, that searcely any plants or animals can exist. On the Antarctic continent-once inhabited by a varied assemblage of plants and doubtless animals-life has been practically exterminated by the outward growth of the great ice-sheet. We have no evidence in geologic history that conditions have ever been especially more severe; and yet in the records of almost every geologic period back to the Archean we find some places which have been glacial and others which have been arid.

Temperatures between $0^{\circ}$ and $80^{\circ}$ Centigrade, at least during the growing season, are required by nearly all living creatures, and for the vast majority of them the range is less than $40^{\circ}$. The polar districts are to-day below the minimum, and much larger areas have been as cold in certain past epochs; but we have no evidence that the maximum has ever been exceeded. This is a very narrow range, and yet the fluctuations of terrestrial climates seem to have been confined within it ever since the Archean period, if not earlier. The writers of the older text-books of geology, placing perhaps too much confidence in the nebular hypothesis of Buffon and La Place, supposed that the temperature of, the earth had constantly decreased from the white heat of an astral period down through an era of molten rock, and a later one of vaporous oceans, to conditions as we find them to-day. The accumulating testimony of the sedimentary strata does not appear to support this supposition. This record, extending back perhaps some hundreds of millions of years, seems to reveal to us a history marked by slight oscillations of climate, but in a broad way singularly uniform and without evidence of a progressive increase or decrease of either general humidity or temperature.

In view of opinions which were generally current a generation ago that geologic history 
revealed a slow but stately progression from smaller to larger continents, from more active mountain-building and volcanic action to quieter conditions, and of warmer, moister climates to colder and drier climates, these results of more recent studies are particularly instructive. The earth's physical history, during the past fifteen or more geologic periods, seems actually to be represented by neither a perceptibly ascending nor a descending curve, but by a slightly wavy line which is either essentially horizontal or more probably is rising or descending so very slowly that all of the recognized periods of the earth's history combined are too short to show the trend.

When we turn to the history of living things' on the earth, however, we have unrolled before us a definite progression which we are accustomed to regard as an upward trend.

Logically, geologists should not include the history of organisms as a part of their science. Such matters should concern the zoologist and botanist. From the outset, however, geologists have been much interested in the study of fossils and the biologists have seldom protested against this adoption. The study of fossil organisms has indeed absorbed nearly all the attention of many men generally regarded as geologists.

No question related to the earth's history arouses greater interest than that of the origin of life. Yet of the beginnings of life we have absolutely no trace in the geologic record. Our notions regarding that remarkable event are necessarily derived from speculations based on the known laws of chemistry and physics, and on the theories of evolution.

Land plants of such familiar types as the ferns and club-mosses we have traced by their fossil remains back to the Devonian or even to the Silurian period. Ages before that, at least as far back as the early part of the Algonkian period, the sedimentary deposits were of such a nature as to strongly indicate that the land was in part covered by an effective mantle of vegetation. This may have been supplied by the mosses and lichens, such as now form that thick and characteristic blanket of the ground in the sub-arctic regions-the "tundra." They would effectively cover the ground, but only under the most favorable circumstances could they be preserved as fossils. Aquatic algæ have been satisfactorily identified in considerable variety in rocks that were laid down early in the Proterozoic era; and there are indirect evidences and perhaps the actual fossil remains of bacteria quite as early. On purely theoretical grounds this has long been expected.

Animals of comparatively advanced classes, such as the arthropods, were highly diversified as far back as the lower Cambrian epoch and have been reported from even older rocks. Simpler animals, such as the radiolarians, have been detected in the pre-Cambrian rocks of France. We may, therefore, reasonably expect to find fossil animals in even the oldest sedimentary rocks, if they are not so altered by metamorphism as to have lost their original structures.

Under the best of circumstances, however, we can hardly hope to find traces of animals more primitive than those represented among groups already known in fossil and living form.

No branch of geologic history has been so assiduously studied as the evolution of the animals. Thanks to this activity, ranging over more than a century, we now have a large fund of information from which to generalize. It has long been recognized that new genera, orders and classes have made their appearance one after another, risen to prominence, flourished for a while, and then declined either to extinction or to a lowly status where some of them have lingered on in obscurity through many succeeding periods. The ammonites, which once inhabited every sea on the globe in great variety, disappeared utterly at the close of the Mesozoic era, and to-day we have nothing more closely related to them than their cousin, the Nautilus. The great class of reptiles, which dominated the land in the Mesozoic era, and whose sway was then apparently unchallenged by any other living thing, has largely disappeared and such types as have survived to the present day have been relegated to the jungles and waste places of the earth, where they must depend for the most part on concealment or upon fleetness to escape from their more powerful enemies. 
Many explanations of these declines and extinctions have been offered-a few absurd, others plausible. Doubtless several causes were involved in the result. But whatever the cause may have been, it is evidently a law of nature that the career of each type and of each group must take the form of a rising and falling curve.

We now clearly understand that in the course of this rise and fall of species, genera, and larger groups, there has been a slow but steady increase in complexity of structure and in function, in both animal and plant bodies. The worm has been succeeded by the more highly constituted mollusk, which has in turn been supplanted by the arthropod, the fish, and finally the mammal.

Each animal type seems to embody an experiment to test the worth of one or more important new devices which are the distinctive contribution of that type to the progress of animal development.

The trilobites in the sea and the insects on land introduced the wholly coordinated nervous system and the power of rapid well-directed motion, with better seeing powers and even the possibility of flight in the air. These improvements represented a great advance over the corals, which wait helplessly for their food to drift into their mouths, or even over such worms, starfishes and mollusks as slowly grope through mud or sand or crawl with proverbial snail's pace over the surface. In a broad sense, the arthropods may be said to have introduced into the world the rapacious habit-the active pursuit of food.

Another advance was represented by the first vertebrates and particularly by the fishes, which have attained nearest to perfection of all water-inhabiting animals either previous or subsequent. They invented the spindle form and the stern propeller, both of which have been imitated necessarily by every successful swimming thing from the shark, the ichthyosaur and the porpoise to the modern submarine torpedo. The fishes also introduced the photographic or image-recording eye, which is far superior to the light-sensitive spots of certain echinoderms or even the remarkable compound eyes of the insects.
The reptiles in their turn devised the solid bony skeleton without which active life upon the dry land had previously been limited to small animals such as the insects. They introduced the encased egg, capable of being incubated in air instead of water. This placed the class one step ahead of the amphibians, which must always remain near water. The reptiles invented also a type of cover which was able to withstand the evaporation of the body liquids, without loss of that flexibility which was essential for rapid motion. They were not, however, so successful in coping with that other element of climate-temperature. The chill of winter reduced their bodily processes to inaction and obliged them to hibernate except in the warmer months in the year. For that reason they must always have been, as they are now, largely confined to the warmer parts of the globe.

The probable descendants of the reptilesthe mammals-somehow contrived that wonderful invention, warm blood, and with it the necessary heat-conserving cover of hair. These enabled the mammals to range over nearly all parts of the globe regardless of elimatic and seasonal changes and to maintain their bodily activities constantly at the most favorable temperature by oxidizing carbohydrates as bodily fuel. It would be hard to overestimate the importance of this innovation.

( $T$ o be concluded)

Eliot Blackwelder

\section{Harvard University}

\section{ON THE DIFFERENTIAL EFFECTS OF THE INFLUENZA EPIDEMIC AMONG NATIVE PEOPLES OF THE PACIFIC ISLANDS}

Since the influenza pandemic of 1917-1918, the writer has had occasion to make two journeys to insular areas of the Pacific Ocean, for the prosecution of special field-studies. In two specific instances, incidental observations were made on the differential effects of the imported disease upon the human inhabitants of certain islands; it is the object of the present brief communication to record the essential facts.

I. The first area is that of the Society 